\title{
The numerical simulation for multistage fractured horizontal well in low-permeability reservoirs based on modified Darcy's equation
}

\author{
Liu Hailong ${ }^{1}$
}

Received: 20 September 2015/ Accepted: 6 September 2016/Published online: 15 September 2016

(C) The Author(s) 2016. This article is published with open access at Springerlink.com

\begin{abstract}
Based on the nonlinear percolation theory, a new nonlinear seepage model of low-permeability reservoir was established and an ideal three-phase and three-dimensional numerical reservoir simulation model for the multistage fractured horizontal well was built. By taking the impacts of pressure-sensitive effect and the threshold pressure gradient into consideration, the quasi-linear numerical model, Darcy numerical model and the non-Darcy numerical model were conducted. Meanwhile, the effects of parameters were fully investigated. The study shows that compared to the results of Darcy model, when taking nonlinear flow into consideration, the result shows higher energy consumption, lower pressure level, smaller liquid production, and slower water cut rising rate. When the injected fluid reaches the wellbore, the flowing bottom hole pressure increases quickly. However, the time of water front reaching the wellbore is different. Hence, when using non-Darcy flow expression, the process can be present precisely. The recovery ratio is positive with the starting pressure gradient of the water phase, but negative with the oil phase. With pressure-sensitive coefficient decreasing, recovery ratio increases quickly. If producing pressure differential is maintained at a proper value, then the effect of the pressure-sensitive coefficient on the permeability is reduced. With the threshold pressure gradient becoming smaller, the recovery ratio becomes higher.
\end{abstract}

Keywords Numerical simulation · Modified darcy's equation - Low permeability

Liu Hailong

478277608@qq.com

1 Research Institute of Petroleum Exploration and Development, Sinopec, Beijing 100083, China

$\begin{array}{ll}\text { List of symbols } \\ p_{l} & \text { Pressure, psia } \\ \Phi_{l} & \text { Net fluid pressure, psia } \\ S_{l} & \text { Saturation } \\ v_{l} & \text { Velocity } \\ \phi & \text { Porosity, fraction } \\ k & \text { Absolute permeability, mD } \\ k_{r l} & \text { Relative permeability } \\ \mu_{l} & \text { Viscosity, cp } \\ B_{l} & \text { Formation value factor, bbl/stb } \\ \rho_{l} & \text { Fluid density, lbm/scf } \\ q_{l} & \text { Source/sink term (wells), MSCF/D } \\ T_{l} & \text { Fluid conductivity } \\ V_{b} & \text { Grid volume } \\ R_{s} & \text { Solution gas-oil ratio } \\ R_{v} & \text { Oil volatility } \\ g & \text { Gravitational acceleration } \\ D & \text { Depth, ft } \\ G_{l} & \text { Threshold pressure gradient, psia/ft } \\ \alpha & \text { Pressure-sensitive coefficient, 1/psia } \\ p_{\text {cow }}, p_{c g o} & \text { Capillary pressures, psia }\end{array}$

Subscript

$l \quad$ Oil $(o)$, gas $(g)$ and water $(w)$ phases

$f \quad$ Fracture

$m$ Matrix

$n \quad$ Matrix and fracture system

\section{Introduction}

Since 1856, Darcy, a French water conservancy engineer (Darcy 1856), through a large number of experiments, introduced Darcy's law; Darcy's law has been used as the basic equation to describe the fluid flow in porous media. 
The theory of seepage flow, based on Darcy's law, has been widely used in the oil industry and other fields. However, in 1869, King Hagen (Gavin 2004) found that nonlinear seepage exist in low-permeability porous media, and in 1924, the former Soviet Union scholar boozlevski (Barenblatt 1960) put forward for the first time that, in some cases, only when the pressure gradient of the fluid in the porous media was more than a starting pressure gradient, fluid seepage occurs. From then on, models of lowspeed and non-Darcy seepage flow developed rapidly (Pascal et al. 1980; Qinglai et al. 1990; Yanzhang 1997; Yuedong and Jiali 2003; Yang et al. 2007; Qiao et al. 2012).

For almost a century, in order to use simple form and definite physical meaning of mathematical language to describe nonlinear seepage phenomenon, plenty of research on the nonlinear seepage flow model has been established. At present, the mathematical descriptions of a low-speed nonlinear seepage phenomenon are mainly divided into three categories: quasi start-up pressure gradient model (quasi-linear flow), section model and continuous model (Zeng et al. 2011; Li and He 2005; Li and Zhu 2013), as shown in Table 1. Quasi start-up pressure gradient model ignores the bending section of the seepage curve. When the displacement pressure gradient is less than the start-up pressure gradient, the fluid in reservoir cannot flow, so the quasi start-up pressure gradient model narrows the scope of the fluid flow in the low-permeability reservoirs; section model does not reflect the nonlinear section of the actual seepage condition, and the error of the numerical simulation is bigger. What is worse, the critical point of linear and nonlinear seepage has to be judged in section model, which is difficult for specific application in reservoir simulation industry; continuous model cannot reflect the phenomenon of minimum start-up pressure gradient.

In the process of the fluid flow in low-permeability and tight porous media, flow pattern does not obey the linear
Darcy percolation law, but shows that there is a minimum start-up pressure gradient of nonlinear seepage. Therefore, the application of conventional reservoir numerical simulation software for low permeability and low-permeability reservoirs has certain restrictions. Cheng and Chen (1998), Guo et al. (2004) set up a mathematical model about oil/ water non-Darcy flow and an invented-nine-spot well pattern of water flooding in the low-permeability reservoir by using finite-difference numerical simulator. Guozhong (2006), Gao et al. (2008) proposed a mathematical model for multi-phase non-Darcy flow, also developed a corresponding finite deference discretization method for this model, and then deduced a well grid flow equation to simulate non-Darcy flow. In addition, some other scholars Yuan et al. (2009), Yao et al. (2014) and Zhang et al. (2014) also studied the numerical simulation method by taking threshold pressure gradient into consideration.

In this paper, based on tight sandstone nonlinear percolation theory, starting from Hagen-Poisuile formula, a new nonlinear seepage model for low-permeability reservoir was established. This new model took the effect of the fluid yield stress and the adsorption of the boundary layer on seepage flow into consideration. The laboratory physical simulation, seepage flow mechanics and numerical computation were used to systematically study the method and application of the nonlinear flow numerical simulation.

\section{Establishment of new nonlinear seepage model}

According to the capillary model and boundary layer theory, the following assumptions were established for the fluid flow in low-permeability reservoir:

1. The fluid exist fluid yield stress;

2. The fluid does laminar flow in a capillary tube;

3. The fluid flow in the capillary can be seen as a steady seepage flow in the changing radius of the capillary;

Table 1 Nonlinear mathematical models of tight oil reservoir

\begin{tabular}{|c|c|c|}
\hline Model & Equation & Specification of the model \\
\hline $\begin{array}{l}\text { Quasi start-up pressure } \\
\text { gradient model }\end{array}$ & $v= \begin{cases}-\frac{k}{\mu}(\nabla p-G) & \nabla p \geq G \\
0 & \nabla p<G\end{cases}$ & When $\nabla p<G$, the velocity cannot be calculated \\
\hline $\begin{array}{l}\text { Exponential form of section } \\
\text { model }\end{array}$ & $v^{n}=-\frac{k}{\mu} \nabla p, n \geq 1$ & The simulation error of the linear segments is large \\
\hline $\begin{array}{l}\text { Formal mathematical } \\
\text { equation }\end{array}$ & $v=-\frac{k}{\mu} \nabla p^{1+n_{d}}, n_{d}=1+\frac{2}{1+\frac{\Delta p L}{G}}$ & $\begin{array}{l}\text { It is difficult to identify the connecting point between the linear region and the } \\
\text { nonlinear region }\end{array}$ \\
\hline $\begin{array}{l}\text { Three-parameter continuous } \\
\text { model }\end{array}$ & $v\left(a_{1}+\frac{a_{2}}{1+b v}\right)=-\nabla p$ & $\begin{array}{l}\text { It cannot reflect the phenomenon of minimum start-up pressure gradient, in } \\
\text { which the real seepage does exist }\end{array}$ \\
\hline $\begin{array}{l}\text { Two-parameter continuous } \\
\text { model }\end{array}$ & $v=-\frac{k}{\mu} \nabla p\left(1-\frac{1}{a+b|\nabla p|}\right)$ & It is unable to show the mutations information of the seepage curve \\
\hline
\end{tabular}


4. The porous media is ideal, which means that there is no difference in geometry, fluid properties and pressure between the porous media and the real rock.

The Hagen-Poisuile formula

$Q=-C \frac{n A \pi r^{4}}{8 \mu \sigma} \nabla p$

where $n$ is the number of the capillaries in the unit crosssectional area, $r$ is the capillary radius, $A$ is the unit of cross-sectional area, $\sigma$ is the fracture length in the unit cross-sectional area, and $C$ is the unit conversion coefficient. When using Darcy metric units, $C=1$.

The radius of pore throat in tight sandstone is tiny, which can be measured by micrometer, so the effect of the fluid yield stress and the adsorption of the boundary layer cannot be ignored. The fluid in the pore adsorbs on the surface of the solid rock, and the adsorption reduces the available flow area and leads to uneven distribution of reservoir fluid. The closer the fluid is from the solid boundary, the greater the degree of influence to the fluid is. The thickness of boundary layer becomes thinner with the displacement pressure rising, the percentage of flowable fluid increasing, as well as the viscosity of the fluid increasing, so the fluid in the pore needs to overcome greater fluid yield stress, which changes the flow of fluid properties and cross-sectional area of the seepage flow. The low-permeability reservoir does not obey Darcy's law but instead shows the characteristics of nonlinear flow. By considering the fluid yield stress and the effect of boundary layer, Eq. (1) can be rewritten as

$Q=-C \frac{n A \pi\left(r-r_{0}\right)^{4}}{8 \mu \sigma}\left(\nabla p-\frac{\tau}{r-r_{0}}\right)$

where $r_{0}$ is the thickness of boundary layer and $\tau$ is the fluid yield stress.

The porosity $(\phi)$ of the capillary model

$\phi=\frac{n \pi r^{2} A}{A}=n \pi r^{2}$

The permeability $(k)$ of the capillary model

$k=\frac{\phi r^{2}}{8}$

Substituting Eqs. (3) and (4) into Eq. (2), Eq. (2) can be rewritten as

$Q=-C \frac{k A}{\mu \sigma}\left(1-\frac{r_{0}}{r}\right)^{4}\left(1-\frac{\tau}{r} \frac{1}{\left(1-\frac{r_{0}}{r}\right) \nabla p}\right) \nabla p$

$\mathrm{Xu}$ and Yue (2007) through experiments proposed that the smaller the diameter is, the more positive the nonlinear flow characteristics are, and the apparent permeability of microtubes increases gradually to a theoretical value with pressure gradient increasing. So by defining

$\frac{r_{0}}{r}=\frac{a_{1}}{\nabla p}<1, \quad \frac{\tau}{r}=a_{2}, \quad \frac{a_{2}}{\nabla p-a_{1}}<\frac{a_{1}+a_{2}}{\nabla p}<1$

where $a_{1}, a_{2}$ are the experimental parameters related to physical properties of low-permeability reservoirs.

Substituting Eq. (6) into Eq. (5), by ignoring high-order infinitely small quantity, Eq. (5) can be rewritten as

$Q=-C \frac{k A}{\mu \sigma}\left(1-\frac{4 a_{1}}{\nabla p}-\frac{a_{2}}{\left(\nabla p-a_{1}\right)}-\frac{4 a_{1} a_{2}}{\nabla p\left(\nabla p-a_{1}\right)}\right) \nabla p$

substituting $\frac{4 a_{1} a_{2}}{\nabla p\left(\nabla p-a_{1}\right)}=\frac{b_{1}}{\nabla p-a_{1}}+\frac{b_{2}}{\nabla p}$ into Eq. (7)

$Q=-C \frac{k A}{\mu \sigma}\left(1-\frac{c_{1}}{\nabla p}-\frac{c_{2}}{\nabla p-c_{3}}\right) \nabla p$

If $c_{1}=c_{2}=0$, Eq. (8) will be Darcy model, if $c_{1} \neq 0$, $c_{2}=0$, Eq. (8) will be quasi start-up pressure gradient model (quasi-linear flow), if $c_{1} \neq 0, c_{2} \neq 0$, Eq. (8) shows three-parameter continuous model, and if $c_{1} \neq 0, c_{2} \neq 0, c_{3} \neq 0$, different curves can be achieved. The characteristics of nonlinear flow in low-permeability reservoirs are well interpreted by Eq. (8).

\section{Parameter description}

The three nonlinear coefficients with profound practical and clear physical meanings can be obtained from the above new model. In Eq. (8), $c_{1}$ and $c_{2}$ are non-Darcy parameters which reflect the effect of fluid properties and the interaction between the fluid and solid. The coefficient $c_{1}$ illustrates that the fluids of low-permeability reservoir flow mainly have to overcome the yield stress, and the coefficient $c_{2}$ indicates the influence of the absorption of the boundary layer on the reservoir fluid. Moreover, because the size of pore throat in tight sandstone is tiny, belonging to the micron level, the microscale effects must be considered. Because of the small size of the reservoir fluids, the small factors (mainly including the scale effect and surface effect) affecting macroscopic flow turn to be the main factors that control the fluid process in low-permeability reservoir. Yield stress, adsorption of the boundary layer and microscale effects are not alone, but they are mutually affected and coupled. Because of microscale effect, the influence of surface force is much larger than the volume force and needs to be regarded as a dominant force. The larger the surface force is, the stronger the reservoir fluid is adsorbed by the boundary constraints. All these nonlinear factors lead the reservoir fluids, show stronger nonlinear fluid flow characteristics and deviate from the Darcy's laws. In addition, the displacement force decreases 
as the strength the binding force increases and thus the reservoir fluid is absorbed more easily by the boundary layer, which can increase the thickness of the boundary layer and exacerbate the microscale effect. All of these indicate that the coefficient $c_{3}$ reflects the coupling and interaction effect very well.

\section{Parameter explanation}

In low-permeability reservoir, because the permeability of porous media changes with the driving pressure gradient, $\left(1-\frac{c_{1}}{\nabla p}-\frac{c_{2}}{\nabla p-c_{3}}\right)$ can be seen as a correction coefficient of permeability. The yield stress and the adsorption of the boundary layer are the reason for that starting pressure gradient exists, and because of interaction between these two factors, the starting pressure is not constant. $\left(\frac{c_{1}}{\nabla p}+\right.$ $\left.\frac{c_{2}}{\nabla p-c_{3}}\right)$ in formula (8) equals 1 and can be seen as the equivalent phase of starting pressure gradient, which indirectly indicates the nature of existence of the starting pressure gradient. In addition, by making $Q=0$ in formula (8), that is $-C \frac{k A}{\mu \sigma}\left(1-\frac{c_{1}}{\nabla p}-\frac{c_{2}}{\nabla p-c_{3}}\right) \nabla p=0$, the $\nabla p=$ $\frac{c_{1}+c_{2}+c_{3}+\sqrt{\left(c_{1}+c_{2}+c_{3}\right)^{2}-4 c_{1} c_{3}}}{2}$. So this value can be seen as the real pressure gradient, namely $\frac{\left(c_{1}+c_{2}+c_{3}\right)+\sqrt{\left(c_{1}+c_{2}+c_{3}\right)^{2}-4} c_{1} c_{2} c_{3}}{2}$.

\section{Validation of the model}

Laboratory experiment is the best way to prove the validation of the seepage models built in this paper. The specific experimental procedure is as follows.

Step1 Take 4 core samples of low-permeability reservoir, and the basic parameters are shown in Table 2

Step2 Get the oil mixture by mixing the kerosene and crude oil in different mass ratios, and the viscosity of the oil mixture is measured at $158{ }^{\circ} \mathrm{K}$. Adjust the mass ratio of the kerosene to crude oil until the viscosity of the oil mixture measured at $158^{\circ} \mathrm{K}$ is $1.4 \mathrm{mPa} \mathrm{s}$

Step3 Compound salt water according to the ratio of $\mathrm{NaCl} / \mathrm{CaCl}_{2} / \mathrm{MaCl}_{2}=7: 0.6: 0.4$, and the viscosity of the salt water is measured at $158{ }^{\circ} \mathrm{K}$. Adjust the compound

Table 2 Parameters of experiment cores

\begin{tabular}{lllll}
\hline $\begin{array}{l}\text { Core } \\
\text { number }\end{array}$ & $\begin{array}{l}\text { Length } \\
(\mathrm{cm})\end{array}$ & $\begin{array}{l}\text { Diameter } \\
(\mathrm{cm})\end{array}$ & $\begin{array}{l}\text { Porosity } \\
(\%)\end{array}$ & $\begin{array}{l}\text { permeability } \\
(\mathrm{mD})\end{array}$ \\
\hline$a$ & 4.815 & 2.5 & 10.16 & 1.789 \\
$b$ & 3.783 & 2.5 & 11.43 & 2.853 \\
$c$ & 3.963 & 2.5 & 12.15 & 6.127 \\
$d$ & 3.529 & 2.5 & 13.31 & 7.751 \\
\hline
\end{tabular}

ratio of $\mathrm{NaCl}, \mathrm{CaCl}_{2}$ and $\mathrm{MaCl}_{2}$ until the viscosity of the salt water measured at $158^{\circ} \mathrm{K}$ is $1.15 \mathrm{mPa}$. Use the experimental device of Fig. 1. By changing the displacement pressure gradient of oil flow to drive the core sample, the quantity of the oil flow is measured at $158^{\circ} \mathrm{K}$. The relationships between pressure gradient and flow were drawn, as shown in Fig. 2.

Figure 2a shows a comparison between the results from the experimental data and calculated results from the model. It can be seen that a nice agreement between calculated results and the experimental data, indicating that the model built in this study produces reliable transient velocity. Figure $2 b$ is used to calculate the nonlinear parameters of this new model, and through curve fitting, the three nonlinear parameters can be calculated, as shown in Table 3

\section{Nonlinear numerical model of multistage fracturing wells}

According to the low-speed and non-Darcy seepage flow law of tight sandstones reservoir built in this paper, the low-speed non-Darcy flow is then introduced into the simulation model to establish three-dimensional numerical simulation software for multistage fractured wells.

\section{Model assumptions}

1. The temperature of the reservoir is constant.

2. The reservoir fluid contains three phases-gas, oil and water, or two phases- the combination from the above three fluids.

3. For matrix system, the flow of oil and water obeys the non-Darcy flow, and the gas flow obeys Darcy flow. For fracture system, three phases gas, oil, and water all obey Darcy flow.

4. The gas phase in the reservoir is free gas or dissolved gas.

5. The oil phase has gas component and oil component existed, and the water phase has dissolved gas component.

6. The time for gas components dissolving or escaping can be ignored.

\section{Mathematical model \\ Seepage equation}

Matrix system 


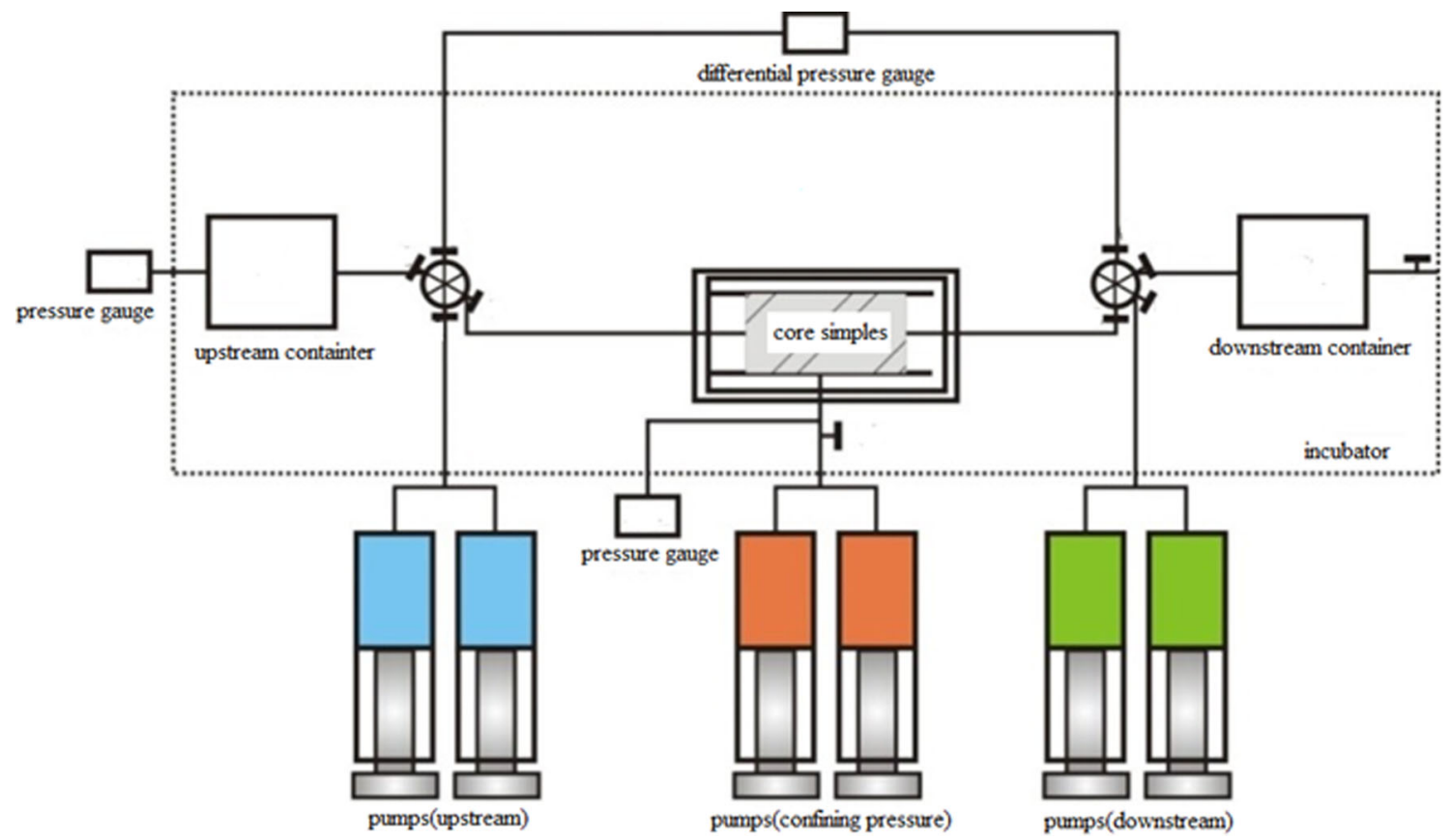

Fig. 1 Schematic diagram of the experimental apparatus a model validation, $\mathbf{b}$ obtaining parameters

$$
\left\{\begin{array}{l}
v_{o m}=C \frac{k_{m} k_{r o m}}{\mu_{o m} \sigma}\left(1-\frac{c_{1 o m}}{\nabla p_{o m}}-\frac{c_{2 o m}}{\nabla p_{o m}-c_{3 o m}}\right) \nabla \Phi_{o m} \\
v_{w m}=C \frac{k_{m} k_{r w f}}{\mu_{w m} \sigma}\left(1-\frac{c_{1 w m}}{\nabla p_{w m}}-\frac{c_{2 w m}}{\nabla p_{w m}-c_{3 w m}}\right) \nabla \Phi_{w m} \\
v_{g m}=C \frac{k_{m} k_{r g m}}{\mu_{g m} \sigma} \nabla \Phi_{g m}
\end{array}\right.
$$

Fracture system

$$
\left\{\begin{array}{l}
v_{o f}=C \frac{k_{f} k_{r o f}}{\mu_{o f} \sigma} \nabla \Phi_{o f} \\
v_{w f}=C \frac{k_{f} k_{r w f}}{\mu_{w f} \sigma} \nabla \Phi_{w f} \\
v_{g f}=C \frac{k_{f} k_{r g f}}{\mu_{g f} \sigma} \nabla \Phi_{g f}
\end{array}\right.
$$

where

$$
\begin{aligned}
& \nabla \Phi_{l m}=p_{l f}-\rho_{l f} g D, \quad l=o, w, g \\
& \nabla \Phi_{l f}=p_{l f}-\rho_{l f} g D, \quad l=o, w, g
\end{aligned}
$$

\section{Continuity equation}

For dual media, the fluid in the low-permeability reservoir exchanges between the matrix and fracture and mainly occurs under a relatively gentle change in formation pressure. Therefore, the process of the exchanging is assumed to be stable, that is, crossflow does not have any relationship with time. In unit time and unit volume, the volume mass of the fluid flowing from the matrix to the fracture merely depends on the viscosity of the fluid, the pressure difference between the pores and fracture, some characteristic quantities of the rock and so on. According to Barenblatt et al. (1960) research

$\mu^{*}=\frac{\varepsilon}{\mu}\left(p_{m}-p_{l}\right)$

Based on the above analysis, the reservoir fluid is composed of three independent phases, including oil, gas and water. Taking the dissolved gas of oil and water into consideration, the continuity equation can be built.

Matrix system

$$
\left\{\begin{array}{l}
-\nabla\left[(\rho v)_{o m}-\left(\rho \mu^{*}\right)_{o m}\right]=\frac{\partial(\phi \rho S)_{o m}}{\partial t} \\
-\nabla\left[(\rho v)_{w m}-\left(\rho \mu^{*}\right)_{w m}\right]=\frac{\partial(\phi \rho S)_{w m}}{\partial t} \\
-\nabla\left[\left(\rho_{o d} v_{o m}+\rho_{w d} v_{w m}+\rho_{g} v_{g m}\right)-\left(\rho_{o d} \mu_{o}^{*}+\rho_{w d} \mu_{w}^{*}+\rho_{g} \mu_{g}^{*}\right)_{m}\right]=\frac{\partial\left[\phi\left(\rho_{o d} S_{o}+\rho_{w d} S_{w}+\rho_{g} S_{g}\right)\right]_{m}}{\partial t}
\end{array}\right.
$$




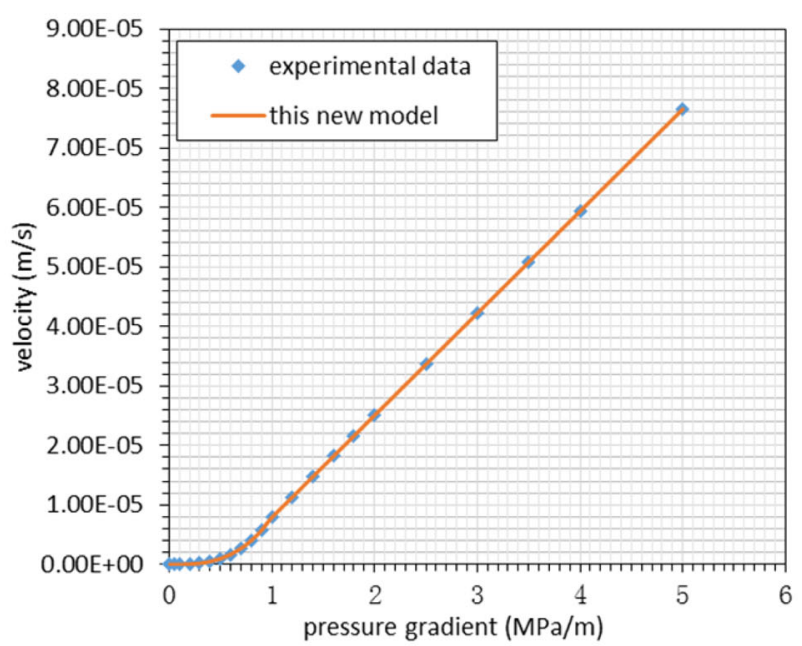

(a) model validation

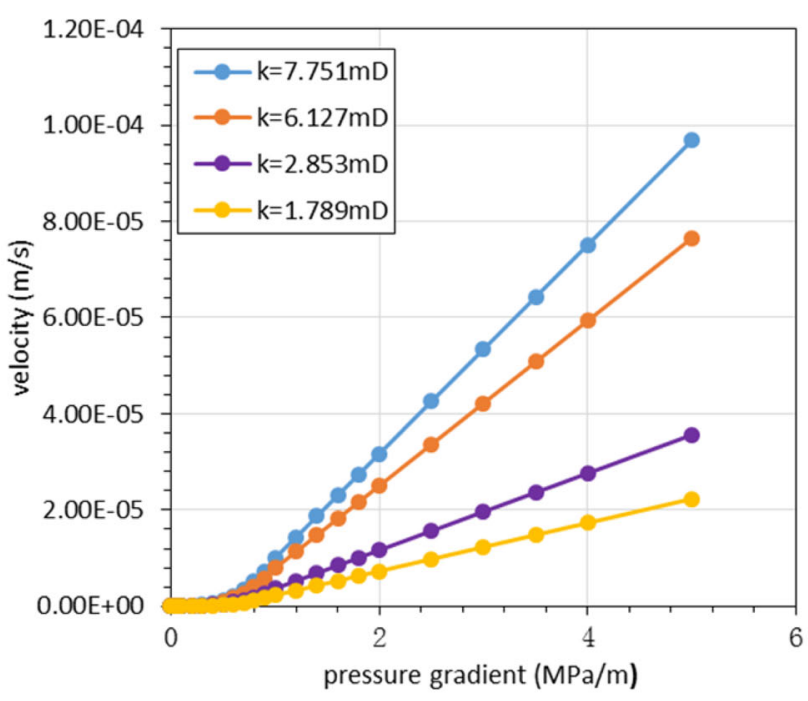

(b) obtaining parameters

Table 3 Results of this new model parameter fitting

\begin{tabular}{llll}
\hline Core number & $c_{1}\left(\mathrm{MPa} \mathrm{m}^{-1}\right)$ & $c_{2}\left(\mathrm{MPa} \mathrm{m}^{-1}\right)$ & $c_{3}\left(\mathrm{MPa} \mathrm{m}^{-1}\right)$ \\
\hline$a$ & 1.331 & -1.041 & -1.386 \\
$b$ & 0.995 & -0.897 & -0.893 \\
$c$ & 0.409 & -0.372 & -0.152 \\
$d$ & 0.281 & -0.262 & -0.074 \\
\hline
\end{tabular}

Eqs. (10) and (13) into Eq. (15), the flow equation of fracture system is obtained.

\section{Auxiliary equation}

Capillary pressure equation

$p_{\text {cgon }}=p_{\text {gn }}-p_{\text {on }}, \quad n=f, m$

$p_{\text {cown }}=p_{\text {on }}-p_{\mathrm{wn}}, \quad n=f, m$

Saturation equation

$S_{o n}+S_{w n}+S_{g n}=1, \quad n=f, m$

Initial condition

$\left\{\begin{array}{l}\left.p_{w}\right|_{t=0}=p_{w i}(x, y, z) \\ \left.S_{w}\right|_{t=0}=S_{w i}(x, y, z) \\ \left.S_{o}\right|_{t=0}=S_{o i}(x, y, z)\end{array}\right.$

The reservoir pressure and the distribution of saturation in different locations are given in the initialization process. Then, it is easy for the iterative solver to solve another time step of reservoir pressure and the distribution of saturation

Constant pressure boundary

$\left.p_{l}\right|_{\Gamma}=$ const $, \quad l=o, w, g$

Closed boundary

$\left.\frac{\partial \Phi_{l}}{\partial n}\right|_{\Gamma}=$ const $, \quad l=o, w, g$

Fracture system

$$
\left\{\begin{array}{l}
-\nabla\left[(\rho v)_{o f}-\left(\rho \mu^{*}\right)_{o f}\right]+q_{o}=\frac{\partial(\phi \rho S)_{o f}}{\partial t} \\
-\nabla\left[(\rho v)_{w f}-\left(\rho \mu^{*}\right)_{w f}\right]+q_{w}=\frac{\partial(\phi \rho S)_{w f}}{\partial t} \\
-\nabla\left[\left(\rho_{o d} v_{o f}+\rho_{w d} v_{w f}+\rho_{g} v_{g f}\right)-\left(\rho_{o d} \mu_{o}^{*}+\rho_{w d} \mu_{w}^{*}+\rho_{g} \mu_{g}^{*}\right)_{f}\right]+q_{g}=\frac{\partial\left[\phi\left(\rho_{o d} S_{o}+\rho_{w d} S_{w}+\rho_{g} S_{g}\right)\right]_{f}}{\partial t}
\end{array}\right.
$$

Substituting Eqs. (9) and (13) into Eq. (14), the flow equation of matrix system is obtained. Substituting
For production wells, the bottom hole pressure or the oil production (rate), the water production (rate) and the liquid 
production (rate) are given. For injection wells, the bottom hole pressure or the injection volume (rate) is given.

\section{Model solution}

\section{Discrete differential}

For the matrix system, introduce the linear differential operator

$\Delta T_{l}^{n} \Delta \Phi_{l}^{n}\left(1-\frac{G}{\left|\nabla \Phi_{l}^{n}\right|}\right)=V_{b} \frac{\partial}{\partial t}\left(\frac{\phi S_{l}}{B_{l}}\right), \quad l=o, w, g$

where

$T_{l}^{n}=\frac{F}{B_{l}} \frac{k_{r l}}{\mu_{l}}, \quad l=o, w, g$

Ignoring the infinitely small quantity in the iterative process, the numerical model of the matrix system can be obtained.

Oil or water component

$$
\begin{aligned}
& \Delta T_{l m}^{n} \Delta \Phi_{l m}^{n}\left(1-\frac{c_{1 m}}{\left|\nabla \Phi_{l m}^{n}\right|}-\frac{c_{2 m}}{\left|\nabla \Phi_{l m}^{n}\right|-c_{3 m}}\right) \\
& -\varepsilon_{l m}\left(\frac{k_{r l} \rho_{l}}{B_{l} \mu_{l}}\right)_{m}\left[\Delta \Phi_{l m}^{n}-\Delta \Phi_{l f}^{n}\right] \\
& =\frac{V_{b}}{\Delta t}\left[\left(\frac{\phi_{m} S_{l m}}{B_{l m}}\right)^{n-1}-\left(\frac{\phi_{m} S_{l m}}{B_{l m}}\right)^{n}\right], \quad l=o, w
\end{aligned}
$$

Gas component

$$
\begin{aligned}
\Delta T_{o m}^{n} R_{s o m}^{n} \Delta \Phi_{o m}^{n}+\Delta T_{w m}^{n} R_{s w m}^{n} \Delta \Phi_{w m}^{n}+\Delta T_{g m}^{n} \Delta \Phi_{g m}^{n} \\
\quad-R_{s o m}^{n} \varepsilon_{o m}\left(\frac{k_{r l} \rho_{l}}{B_{l} \mu_{l}}\right)_{m}\left[\Delta \Phi_{l m}^{n}-\Delta \Phi_{l f}^{n}\right] \\
\quad-R_{s w m}^{n} \varepsilon_{w m}\left(\frac{k_{r l} \rho_{l}}{B_{l} \mu_{l}}\right)_{m}\left[\Delta \Phi_{l m}^{n}-\Delta \Phi_{l f}^{n}\right] \\
\quad-\varepsilon_{g m}\left(\frac{k_{r l} \rho_{l}}{B_{l} \mu_{l}}\right)_{m}\left[\Delta \Phi_{l m}^{n}-\Delta \Phi_{l f}^{n}\right] \\
=\frac{V_{b}}{\Delta t}\left[\left(\phi_{m} \rho_{o m} R_{s o m} S_{o m}+\phi_{m} \rho_{w m} R_{s w m} S_{w m}+\phi_{m} \rho_{g m} S_{g m}\right)^{n-1}\right. \\
\left.\quad-\left(\phi_{m} \rho_{o m} R_{s o m} S_{o m}+\phi_{m} \rho_{w m} R_{s w m} S_{w m}+\phi_{m} \rho_{g m} S_{g m}\right)^{n}\right]
\end{aligned}
$$

For the fracture system, introduce the finite-difference operators.

Ignoring the infinitely small quantity in the iterative process, the numerical model of the fracture system can be obtained.

Oil or water component

$$
\begin{array}{r}
\Delta T_{l f}^{n} \Delta \Phi_{l f}^{n}+\varepsilon_{l f}\left(\frac{k_{r l} \rho_{l}}{B_{l} \mu_{l}}\right)_{f}\left[\Delta \Phi_{l m}^{n}-\Delta \Phi_{l f}^{n}+Q_{l}^{n}\right. \\
\left.=\frac{V_{b}}{\Delta t}\left[\left(\frac{\phi_{f} S_{l f}}{B_{l f}}\right)^{v}\left(\frac{\phi_{f} S_{l f}}{B_{l f}}\right) n\right]\right], \quad l=o, w
\end{array}
$$

Gas component

$$
\begin{aligned}
\Delta T_{o f}^{n} R_{s o f}^{n} \Delta \Phi_{o f}^{n}+\Delta T_{w f}^{n} R_{s w f}^{n} \Delta \Phi_{w f}^{n}+\Delta T_{g f}^{n} \Delta \Phi_{g f}^{n} \\
\quad+R_{s o f}^{n} \varepsilon_{o f}\left(\frac{k_{r l} \rho_{l}}{B_{l} \mu_{l}}\right)_{f}\left[\Delta \Phi_{l m}^{n}-\Delta \Phi_{l f}^{n}\right] \\
\quad+R_{s w f}^{n} \varepsilon_{w f}\left(\frac{k_{r l} \rho_{l}}{B_{l} \mu_{l}}\right)_{f}\left[\Delta \Phi_{l m}^{n}-\Delta \Phi_{l f}^{n}\right] \\
\quad+\varepsilon_{g f}\left(\frac{k_{r l} \rho_{l}}{B_{l} \mu_{l}}\right)_{f}\left[\Delta \Phi_{l m}^{n}-\Delta \Phi_{l f}^{n}\right] \\
=\frac{V_{b}}{\Delta t}\left[\left(\phi_{f} \rho_{o f} R_{s o f} S_{o f}+\phi_{f} \rho_{w f} R_{s w f} S_{w f}+\phi_{f} \rho_{g f} S_{g f}\right)^{n-1}\right. \\
\left.\quad-\left(\phi_{f} \rho_{o f} R_{s o f} S_{o f}+\phi_{f} \rho_{w f} R_{s w f} S_{w f}+\phi_{f} \rho_{g f} S_{g f}\right)^{n}\right]
\end{aligned}
$$

Darcy model is calculated by correcting the crossflow factor Kazemi

de Swaan (1976) calculated the crossflow factor of the Darcy model by using the following equation.

$\varepsilon=4\left(\frac{k_{x}}{L_{x}^{2}}+\frac{k_{y}}{L_{y}^{2}}+\frac{k_{z}}{L_{z}^{2}}\right)$

Modifying Eq. (28), the formula to calculate the crossflow factor of the new model built in this paper can be written as

$\varepsilon=4\left(\frac{k_{x} M_{x l}}{L_{x}^{2}}+\frac{k_{y} M_{y l}}{L_{y}^{2}}+\frac{k_{z} M_{z l}}{L_{z}^{2}}\right), \quad l=o, w, g$

where

$$
\begin{aligned}
M_{i l}= & 1-\frac{c_{1 l}}{\left(\Phi_{l m}-\Phi_{l f}\right) /\left(0.5 L_{i}\right)} \\
& -\frac{c_{2 l}}{\left(\Phi_{l m}-\Phi_{l f}\right) /\left(0.5 L_{i}\right)-c_{3 l}}, \\
i= & x, y, z ; \quad l=o, w, g
\end{aligned}
$$

\section{Solution to numerical model}

Using differential method, the nonlinear equations of pressure and saturation are established. The method of alternating iteration is used to solve these equations.

Stepl In the progress of iterative calculation, the value of the initial pressure and saturation is given in the equations.

Step2 Linearize the coefficient of nonlinear equations, and iterative method is used to solve these linear equations, and, respectively, the value of pressure and saturation is obtained in the next one unit. 
Step3 Continue with Step2, and the values of pressure and saturation are obtained in every unit.

Step4 Calculate the value of the pressure gradient and pressure changes in each unit.

Step5 Use the nonlinear flow correction coefficient to calculate conductivity, and update the coefficient matrix.

Step6 Use the updated coefficient matrix to recalculate the value of pressure and saturation.

Step7 Repeat Steps1-6 until the value of pressure and saturation become stable and meet accuracy requirements. The values of pressure and saturation obtained at this time step are the initial values of pressure and saturation for the next time step.

Step8 Go to the calculation of the next time step, and repeat Steps1-7; then, the value of pressure and saturation for each time step can be obtained.

According to the difference equation and the above solving step, by combining the solving flowchart (Fig. 3) and the related theory, the three-phase and three-dimensional low-permeability reservoir simulation software is developed. This software is based on Visual Basic 6.0, ACCESS, WORD and EXCEL technology. It can meet the needs of the project of oil and gas development. The software also provides basic functions, such as mapping, data computation, data analysis and so on. It is suitable for Microsoft Office 32-bit and 64-bit. This IDRS-NVR Client Software can support the numerical simulation of lowpermeability reservoirs.

\section{Model application}

\section{Effect of nonlinear coefficient on seepage}

In the numerical simulation, a plane flooding unit composed of one injector with one producer was employed. The layer was $3 \mathrm{~m}$ high. The distance between the injector and the producer was $300 \mathrm{~m}$. The method of the blockcentered grid was used to divide grids. The number of grids in $X$ direction is 63, in $Y$ direction is 44, and in $Z$ direction is 5 , so the total number of grids is 13,860 . In horizontal plane (including $X$ and $Y$ directions), the grid spacing is $5 \mathrm{~m}$, and in the vertical plane, the grid spacing is $4 \mathrm{~m}$. The time step is 30 days, and the permeability is homogeneous, and the porosity is $7.9 \%$. By setting different nonlinear coefficients, different models can be simulated. We can easily get Darcy model if $c_{1}=c_{2}=0 \mathrm{MPa} \mathrm{m}^{-1}$, and quasilinear model if $c_{1}=1.331 \mathrm{MPa} \mathrm{m}^{-1}, c_{2}=0 \mathrm{MPa} \mathrm{m}^{-1}$ and non-Darcy model if $c_{1}=1.331 \mathrm{MPa} \mathrm{m}^{-1}, c_{2}=$ $-1.041 \mathrm{MPa} \mathrm{m}^{-1}, \quad c_{3}=-1.386 \mathrm{MPa} \mathrm{m}^{-1}$. The main

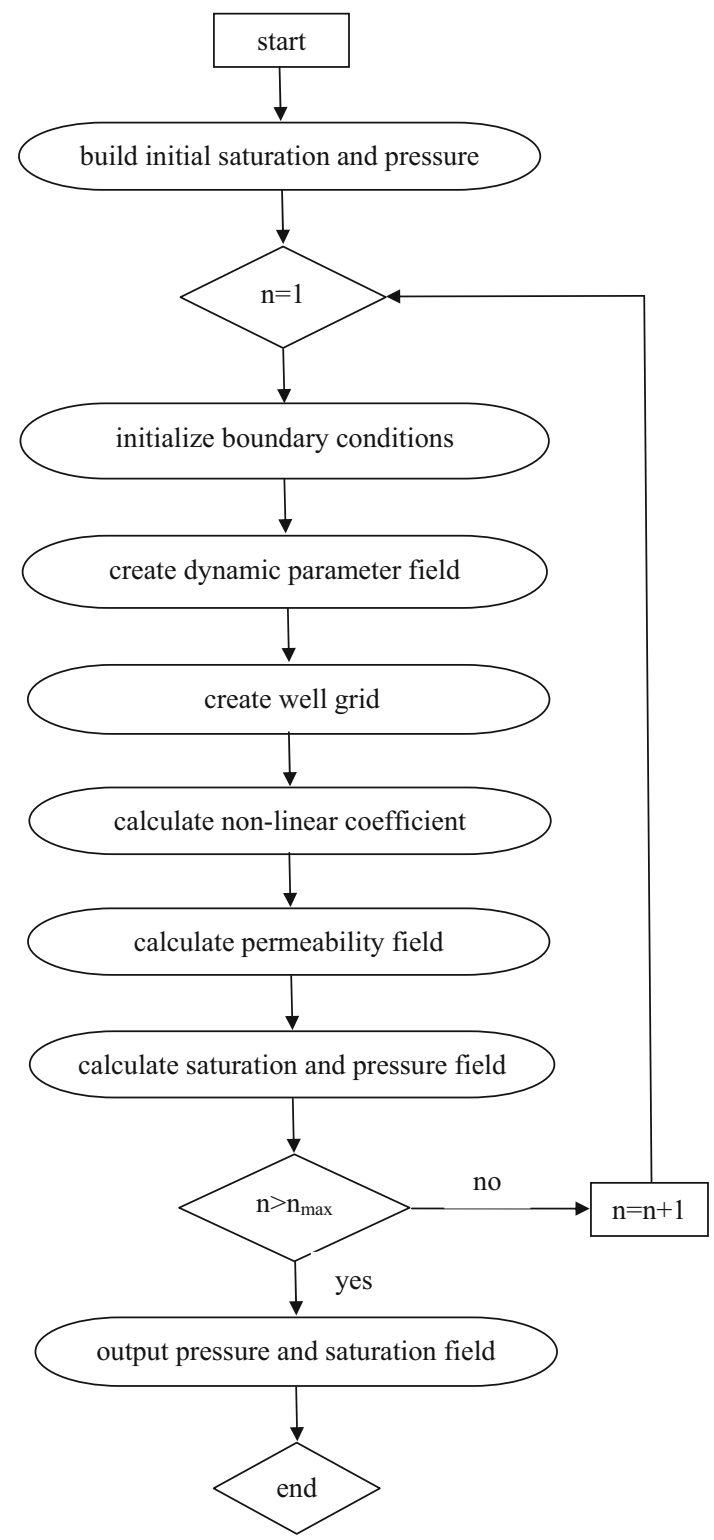

Fig. 3 Flowchart for solving numerical model of low-permeability reservoir

parameters of static geological model are shown in Table 4, and the main parameters of the fluid model are shown in Table 5. The curve of oil and water relative permeability is shown in Fig. 4.

Improving recovery factor via multistage fracture well and the technology of water flooding. The reservoir bed is completely shot, and the oil wells produce fluid under the condition of constant oil rate. After producing for 30 days, the distribution of reservoir pressure near the wellbore is shown in Fig. 5. Figure 5 shows that when considering nonlinear seepage, the pressure drops much quickly, and the pressure drop funnel is bigger because of the increasing flow resistance in the flow process. The pressure gradient is bigger in Darcy model and smaller in non-Darcy model. 
Table 4 Main parameters of static geological model

\begin{tabular}{llll}
\hline Parameters & Value & Parameters & Value \\
\hline Top depth & $3000 \mathrm{~m}$ & Porosity & $17.2 \%$ \\
Fracture permeability & $4.27 \mathrm{mD}$ & Matrix permeability & $0.43 \mathrm{mD}$ \\
Oil-water interface & $3004 \mathrm{~m}$ & Effective thickness & $4 \mathrm{~m}$ \\
\hline
\end{tabular}

What is more, most of the flowing regions belong to the nonlinear segment. So, it is more accurate to simulate the pressure performance in low-permeability reservoir with the new non-Darcy simulation model built in this paper.

Comparing Fig. 5b, c, it is clear that the nonlinear coefficients have less effect on the pressure field, but these have some impact on the bottom hole pressure. The bottom hole pressure drops significantly (Fig. 6). The bottom hole pressure drops fast in the Darcy model, but most slowly in the quasi-linear model. Besides, the time of that the bottom hole pressure to reach the lowest point is different, because different models treat the formation resistance variously. As for the water cut (Fig. 7), the Darcy model rises the most quickly, then the quasi-linear model ranks the second, and the non-Darcy model rises more slowly.

Darcy model does not take the threshold pressure gradient and nonlinear segment resistance into consideration and significantly underestimates the flow resistance of fluid flow in the low-permeability reservoir formation. So Darcy model overestimates the flow capability of fluid in porous media, making the recovery factor the biggest (Fig. 8). On the contrary, the quasi-linear model exaggerates the flow resistance of fluid flow in the reservoir, which makes the recovery factor the lowest in low-permeability reservoir. However, the simulation of non-Darcy model not only takes the nonlinear segment into account, but also considers the threshold pressure gradient. The water breakthrough time becomes longer, and the water drive efficiency is lower, which is the reason why this is a job site, injection wells inject a large amount of infusion, but the oil well production slightly increases. All the above indicates the practical recovery factor should be between the Darcy model and quasi-linear model. Therefore, it is

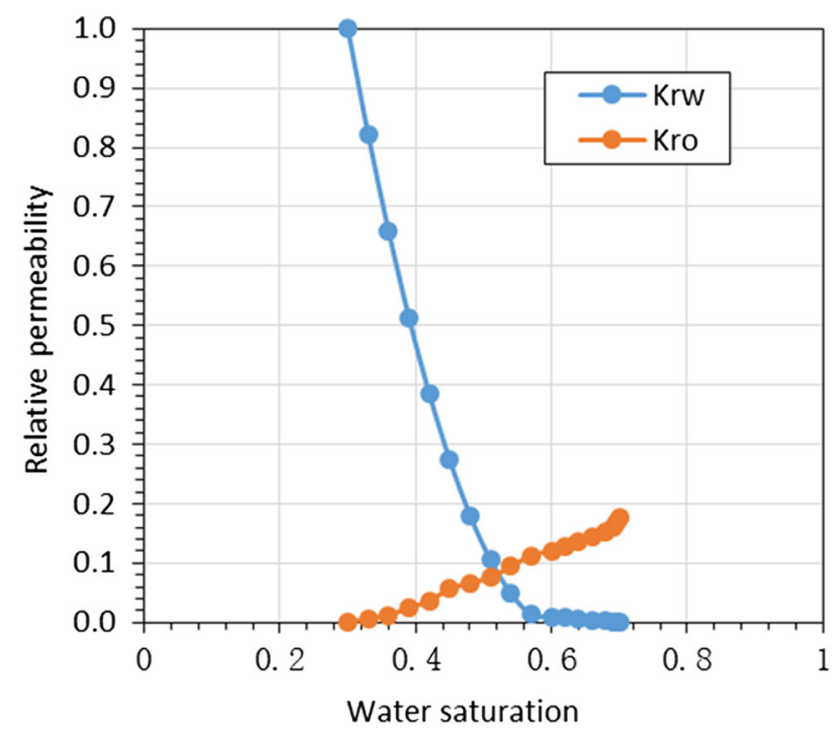

Fig. 4 Curve of oil-water relative permeability

reasonable to evaluate the low-permeability reservoirs with non-Darcy model. In the process of low-permeability reservoir development, the non-Darcy phenomenon cannot be ignored.

\section{Sensitivity analysis}

\section{Starting pressure}

In order to study the influence of the displacing phase and displaced phase start-up pressure on recovery factor, the effect of start-up pressure gradient about oil phase and water phase on the recovery factor was studied. The effect of start-up pressure gradient about oil phase on the recovery factor is shown in Fig. 9. It shows that the higher the oil-phase start-up pressure gradient is, the lower the recovery factor is. The impact of water-phase start-up pressure gradient on the recovery factor is shown in Fig. 10, and Fig. 10 shows that the higher the water-phase start-up pressure gradient is, the higher the recovery is. It can be seen that the recovery factor is positive with the water-phase start-up pressure gradient, but negative with

Table 5 Main parameters of the fluid model

\begin{tabular}{llll}
\hline Parameters & Value & Parameters & Value \\
\hline Saturation pressure & $10 \mathrm{MPa}$ & Formation temperature & $135.4{ }^{\circ} \mathrm{F}$ \\
Oil viscosity & $2.3 \mathrm{mPa} \mathrm{s}$ & Water viscosity & $1.4 \mathrm{mPa} \mathrm{s}$ \\
Oil density & $0.8 \mathrm{~g} / \mathrm{cm}^{3}$ & dissolved gas and oil ratio & $28.47 \mathrm{~m}^{3} / \mathrm{m}^{3}$ \\
Water compressibility & $5.1 \times 10^{-4} \mathrm{MPa}^{-1}$ & Oil compressibility & $7.9 \times 10^{-4} \mathrm{MPa}^{-1}$ \\
Oil volume coefficient & $1.17 \mathrm{~m}^{3} / \mathrm{m}^{3}$ & Rock Compressibility & $4.4 \times 10^{-4} \mathrm{MPa}^{-1}$ \\
Number of fractures & 7 & Fracture conductivity & $470 \mathrm{mD} \mathrm{m}$ \\
\hline
\end{tabular}




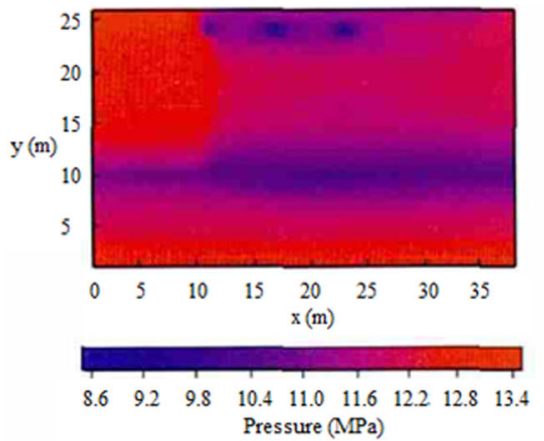

(a) Darcy model

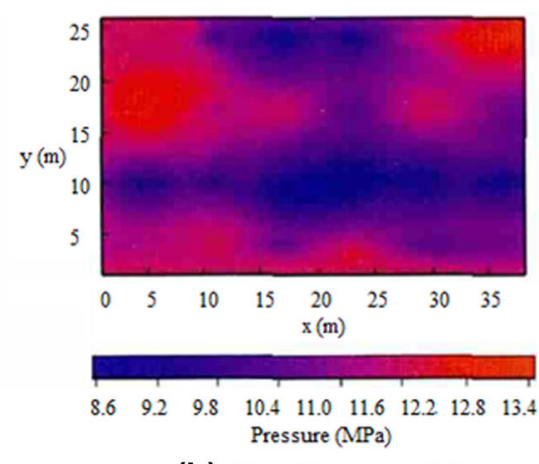

(b) Non-Darcy model

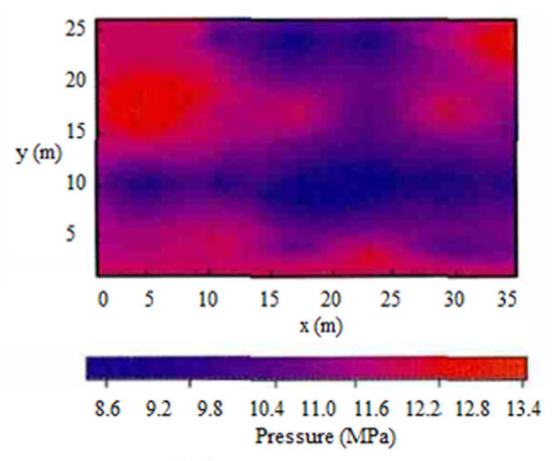

(c) Quasi-linear model

Fig. 5 Pressure distribution of different models

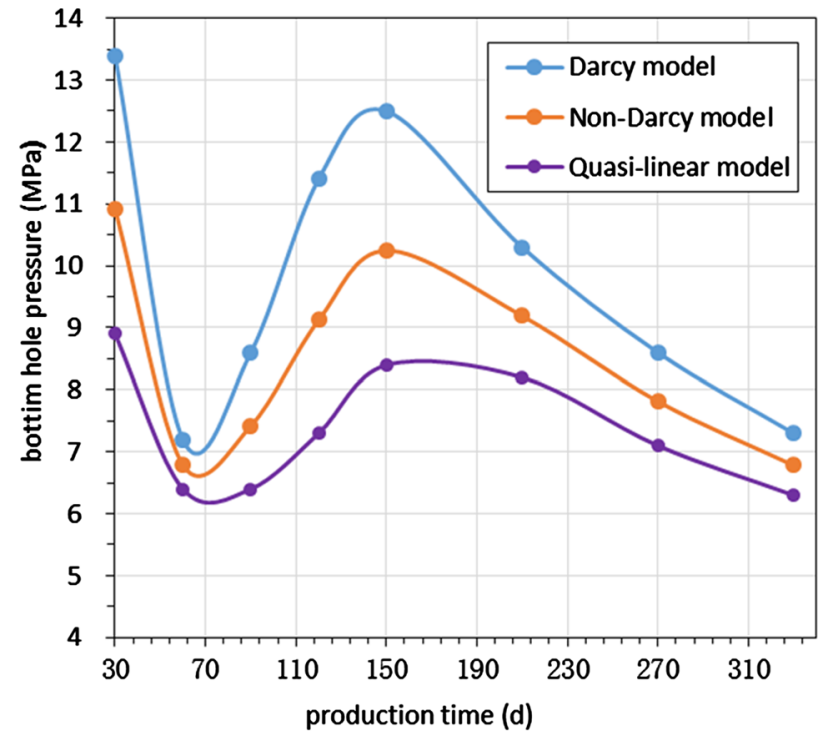

Fig. 6 Bottom hole pressure of different models

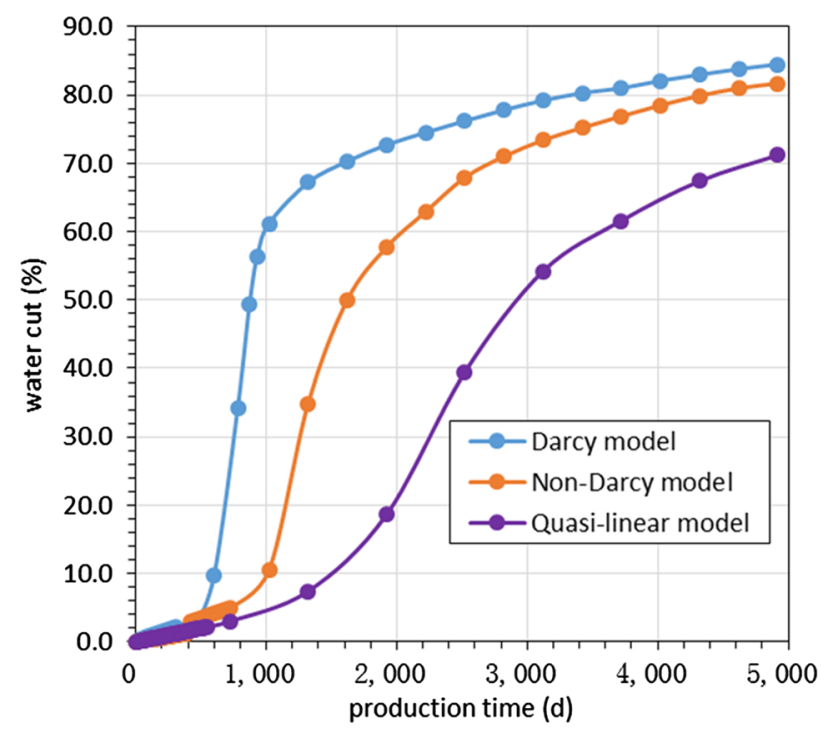

Fig. 7 Water cut of different models

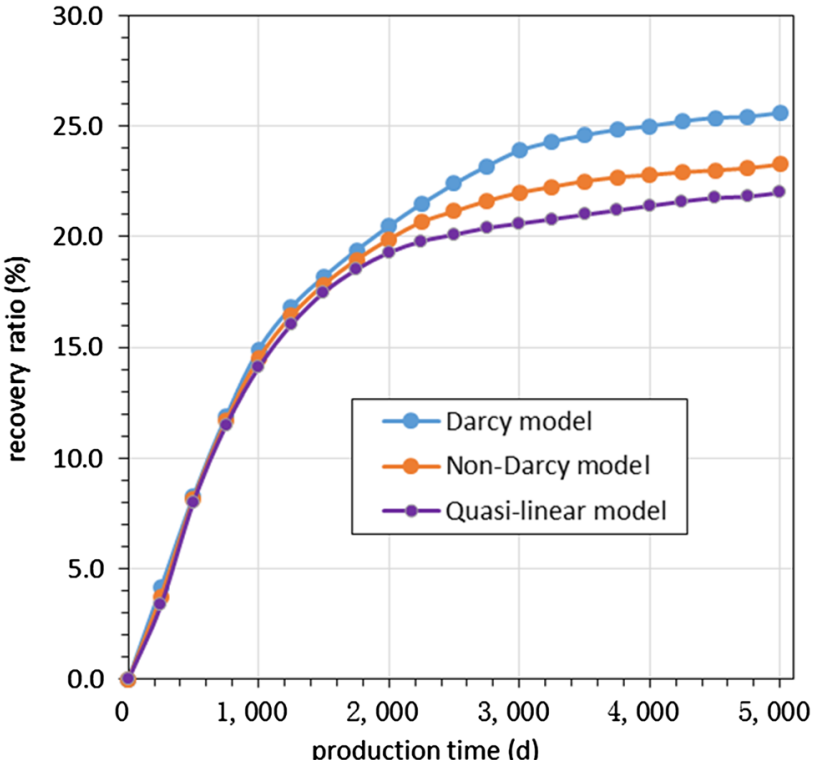

Fig. 8 Recovery ratio of different models

the oil-phase start-up pressure gradient. For the magnitude of the impact on recovery factor, oil-phase start-up pressure gradient is much bigger than water's. The higher the oilphase start-up pressure gradient is, the bigger the reservoir fluid seepage resistance is and the more difficult the reservoir fluid is to flow. On the contrary, the water flow capacity is relatively increasing, and the faster the water cut rate rises, the lower the recovery factor is. Meanwhile, the higher the water-phase start-up pressure gradient is, the bigger the displacement force is. So the oil flow capacity is relatively increasing, and the more slowly the water cut rate rises, the higher the recovery factor is. Generally speaking, when the permeability decreases (increases), the start-up pressure of oil and water phase increases (decreases) at the same time. However, the start-up pressure gradient of oil phase plays a leading role on recovery factor. 


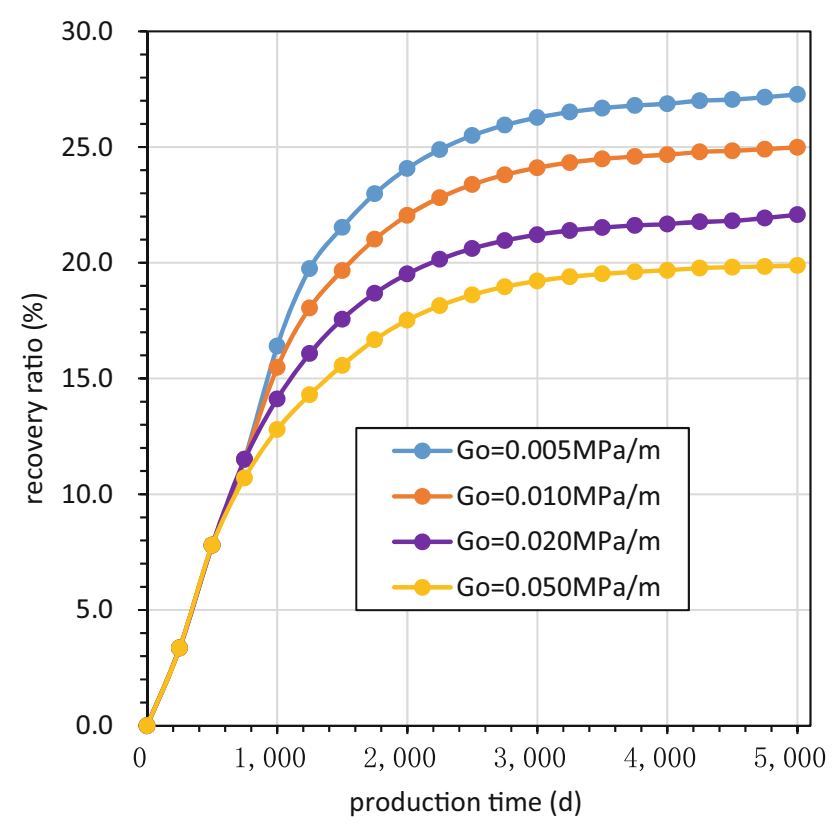

Fig. 9 Effect of oil-phase starting pressure gradient on recovery

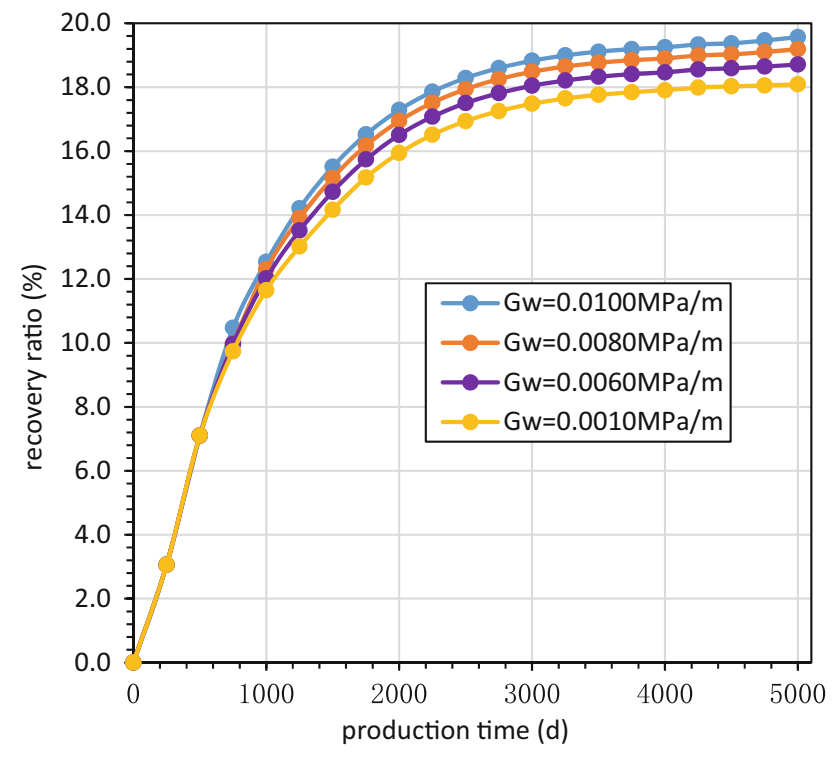

Fig. 10 Effect of water-phase starting pressure gradient on recovery

\section{Pressure sensitivity}

The method of setting different stress sensitivity coefficient is used to study the changing magnitude of permeability influence on recovery factor (Fig. 11). Figure 11 shows that with the increasing of pressure-sensitive coefficient, the changing magnitude of permeability increases, and the recovery factor gradually drops. The pressure nearby the production wells drops and is lower than the initial value,

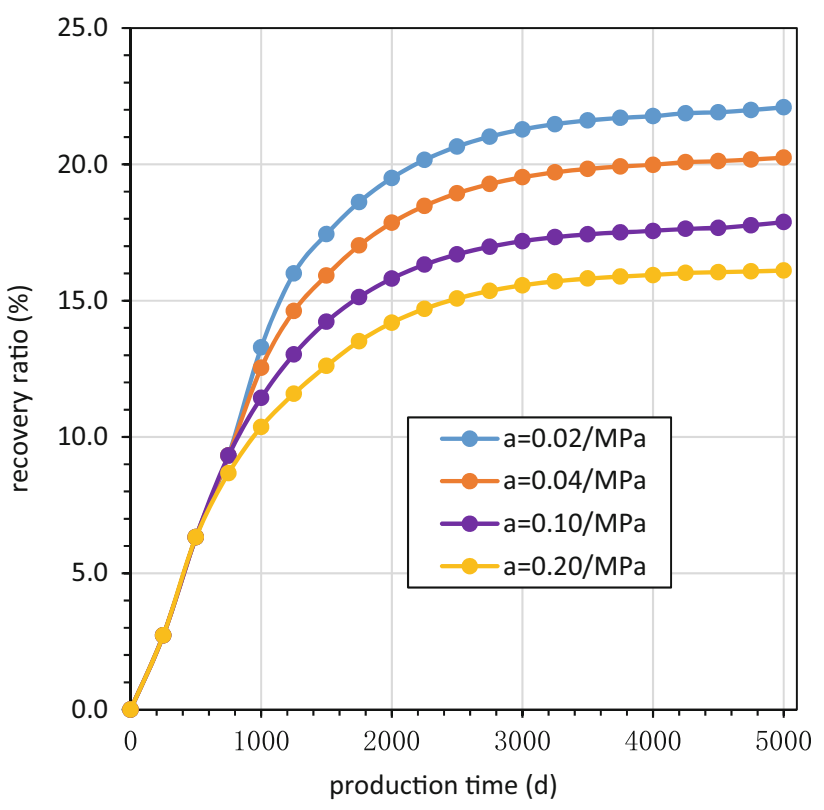

Fig. 11 Effect of pressure-sensitive coefficient on recovery

and pressure drop also causes the permanent loss of permeability growing. So when the value of effective permeability is smaller, water cut rate rises more quickly and finally lessens the recovery factor. When the permeability change width is the same, the greater the permeability is, the less the loss of the effective permeability is after multiple rounds of pressure dropping. The higher the effective permeability is, the more slowly the water cut rate rises and the higher the recovery factor is.

\section{Conclusion}

According to the data of oil field testing and experimental study, based on nonlinear flow law, the mathematical model and numerical model of nonlinear flow were established. It is efficient to solve linear flow and nonlinear flow problem. It can also be used to describe nonlinear relationship using experience formula and numerical method. The solution of nonlinear flow factor came from numerical method and experience.

Darcy model does not take the threshold pressure gradient and nonlinear segment resistance into consideration, which reduces the flow resistance of fluid flow in the lowpermeability reservoir formation, while the quasi-linear model exaggerates the flow resistance of fluid flow in the reservoir. The simulation of the non-Darcy model built in this paper not only takes the nonlinear segment into account but also considers the threshold pressure gradient. Thus, the non-Darcy model built in this paper can evaluate the low-permeability reservoirs effectively and accurately. 
Acknowledgments This article was supported by The Development of Continental Sedimentary Reservoir Simulation System of Beijing (Grant No. Z121100004912001) and The Development of a New Generation of Reservoir Simulation Software of CNPC (2011A1010). The authors would like to acknowledge support received from the RIPED, PetroChina.

\section{Compliance with ethical standards}

Conflict of interests The authors declare there is no conflict of interest regarding the publication of this paper

Open Access This article is distributed under the terms of the Creative Commons Attribution 4.0 International License (http:// creativecommons.org/licenses/by/4.0/), which permits unrestricted use, distribution, and reproduction in any medium, provided you give appropriate credit to the original author(s) and the source, provide a link to the Creative Commons license, and indicate if changes were made.

\section{References}

Barenblatt GI (1960) Basic concepts in the theory of seepage of homogeneous liquids in fissured roeks. J Appl Math Mech 24(5):1285-1300

Barenblatt GE, Zheltov IP, Kochina IN (1960) Basic concepts in the theory of homogeneous liquids in fissured rocks. J Appl Math Mech 24:286-1303

Cheng S, Chen M (1998) Numerical simulation of two-dimensional two-phase non-Darcy slow flow. Pet Explor Dev 25(1):41-44

Darcy HPG (1856) Les Fontaines Publiques de la Ville de Dijon, Exposition et Application desprinecipes a Suivre et des Furnules a Employer dans les Questions de Distribution d'Eau, VietorDalmont, Paris

de Swaan OA (1976) Analytic solutions for determining naturally fractured reservoir properties by well testing. SPE 5346

Gao C, Zhang H, Yang W et al (2008) Development of threedimensional and two-phase numerical reservoir simulation software for non-linear fluid flow through porous medium. J Wuhan Univ Technol 30(2):122-124
Gavin L (2004) Pre-Darcy flow: a missing piece of improved oil recovery puzzle. SPE 89433

Guo Y, Lu D, Ma L (2004) Numerical simulation of fluid flow in low permeability reservoir using finite difference method. J Hydrodyn 19(3):287-292

Guozhong Z (2006) Numerical simulation of 3D and three-phase flow with variable start-up pressure gradient. Acta Pet Sin 27(S):119-124

Li Z, He S (2005) Non-Darcy percolation mechanism in low permeability reservoir. Spec Oil Gas Reserv 12(2):35-40

Li C, Zhu S (2013) Re-discussion on starting pressure gradient. Lithol Reserv 25(4):1-5

Pascal F et al (1980) Consolidation with threshold gradient. Int J Num Anal Methods Geomech 5(3):547-561

Qiao W, Wang L, Zhigang Z et al (2012) Pressure wave propagation of fracturing well in ultra low permeability reservoir. XinJiang Pet Geol 33(2):196-197

Qinglai Y, Qiuxuan H, Wei L et al (1990) A laboratory study on percolation characteristics of single phase flow in low permeability reserviors. J Xi'An Pet Inst 5(2):1-6

$\mathrm{Xu} \mathrm{S}$, Yue X (2007) Experimental research on nonlinear flow characteristics at low velocity. J China Univ Pet 31(5):60-63

Yang Q, Yang Z, Wang Y et al (2007) Study on flow theory in ultralow permeability oil reservoir. Drill and Prod Technol 30(6):52-54

Yanzhang H (1997) Nonliear percolation feature in low permeability reservoir. SOGR 4(1):9-14

Yao J, Huang T, Huang Z (2014) Numerical Simulation of Nonlinear Flow in Heterogeneous and Low-permeability Reservoirs. Chin J Comput Phys 31(5):552-558

Yuan Y, Uang D, Rui H (2009) The numerical simulation and analysis of three-dimensional seawater intrusion and protection projects in porous media. Sci China Ser G Phys Mech Astron 52(1):92-107

Yuedong Y, Jiali G (2003) Non-steady flow in low permeability reservior. Coll Pet Eng Univ Pet China Beijing 27(2):55-58

Zeng B, Cheng L, Li C (2011) Low velocity non-linear flow in low permeability reservoir. Petrol Sci Eng 80(1):1-6

Zhang X, Yang R, Zhongchao Y et al (2014) Numerical simulation method of nonlinear flow in low permeability reservoirs. J Chongqing Univ Sci Technol 16(2):56-59 